\title{
Pyrrolidine dithiocarbamate activates the Nrf2 pathway in astrocytes
}

\author{
Jeffrey R. Liddell ${ }^{1,2}$, Sarka Lehtonen ${ }^{3}$, Clare Duncan ${ }^{1,2}$, Velta Keksa-Goldsteine ${ }^{3}$, Anna-Liisa Levonen ${ }^{4}$, \\ Gundars Goldsteins ${ }^{3}$, Tarja Malm³ ${ }^{3}$ Anthony R. White ${ }^{1,2}$, Jari Koistinaho ${ }^{3}$ and Katja M. Kanninen ${ }^{3^{*}}$
}

\begin{abstract}
Background: Endogenous defense against oxidative stress is controlled by nuclear factor erythroid 2-related factor 2 (Nrf2). The normal compensatory mechanisms to combat oxidative stress appear to be insufficient to protect against the prolonged exposure to reactive oxygen species during disease. Counterbalancing the effects of oxidative stress by up-regulation of Nrf2 signaling has been shown to be effective in various disease models where oxidative stress is implicated, including Alzheimer's disease. Stimulation of Nrf2 signaling by small-molecule activators is an appealing strategy to up-regulate the endogenous defense mechanisms of cells.

Methods: Here, we investigate Nrf2 induction by the metal chelator and known nuclear factor-kB inhibitor pyrrolidine dithiocarbamate (PDTC) in cultured astrocytes and neurons, and mouse brain. Nrf2 induction is further examined in cultures co-treated with PDTC and kinase inhibitors or amyloid-beta, and in Nrf2-deficient cultures.

Results: We show that PDTC is a potent inducer of Nrf2 signaling specifically in astrocytes and demonstrate the critical role of Nrf2 in PDTC-mediated protection against oxidative stress. This induction appears to be regulated by both Keap1 and glycogen synthase kinase 3 $\beta$. Furthermore, the presence of amyloid-beta magnifies PDTC-mediated induction of endogenous protective mechanisms, therefore suggesting that PDTC may be an effective Nrf2 inducer in the context of Alzheimer's disease. Finally, we show that PDTC increases brain copper content and glial expression of heme oxygenase-1, and decreases lipid peroxidation in vivo, promoting a more antioxidative environment.
\end{abstract}

Conclusions: PDTC activates Nrf2 and its antioxidative targets in astrocytes but not neurons. These effects may contribute to the neuroprotection observed for PDTC in models of Alzheimer's disease.

Keywords: Oxidative stress, Alzheimer's disease, Copper, Metal

\section{Background}

Oxidative stress results from an imbalance in the production and removal of reactive oxygen species (ROS) [1-3] and leads to induction of defensive gene expression that aims to detoxify ROS and promote cell survival [4]. An important transcription factor in the defense against oxidative stress is nuclear factor erythroid 2related factor 2 (Nrf2). Nrf2 binds to the antioxidant response element (ARE) and induces the expression of ARE-driven cytoprotective genes, including heme oxygenase-1 (HO-1), NAD(P)H:quinone oxidoreductase1 (NQO1), and glutamate-cysteine ligase (GCL), the rate-

\footnotetext{
*Correspondence: katja.kanninen@uef.fi

${ }^{3}$ Department of Neurobiology, A.I. Virtanen Institute for Molecular Sciences, University of Eastern Finland, Kuopio, Finland

Full list of author information is available at the end of the article
}

limiting enzyme of glutathione synthesis consisting of catalytic (glutamate-cysteine ligase catalytic subunit (GCLC)) and modifier (glutamate-cysteine ligase modifier subunit (GCLM)) subunits [5-7]. Nuclear Nrf2 abundance is regulated by positive and negative stimuli that affect nuclear import and export, binding to the ARE, and degradation $[8,9]$. In the central nervous system, it appears that astrocytes, the most abundant glial cell type that possess important functions in the maintenance of brain homeostasis, have been implicated as the main target of Nrf2 activation [10] and increase their release of glutathione in response to Nrf2 activation [11].

During aging and disease, the normal compensatory mechanisms to combat ROS-mediated damage appear to be insufficient. Consistent with this, the level of nuclear Nrf2 is reduced in the hippocampus of Alzheimer's 
disease (AD) brain [12], and attenuation of the Nrf2ARE pathway coincides with disease progression in transgenic AD mice [13, 14], while genetic ablation of Nrf2 increases $\mathrm{AD}$-associated pathology in $\mathrm{AD}$ mice [15]. Conversely, we have earlier shown that long-term overexpression of Nrf2 specifically in hippocampal neurons ameliorates memory deficits in a mouse model of AD [16] and transduction of primary neurons with Nrf2 protects against amyloid-beta $(\mathrm{A} \beta)$ toxicity [13].

In addition to overexpression, stimulation of the Nrf2ARE pathway by small-molecule activators appears an appealing strategy to up-regulate the endogenous defense mechanisms of cells. At least nine classes of Nrf2-inducing agents have been described [17] with sulforaphane and tertbutylhydroquinone the most widely studied in the central nervous system [9, 18-20]. Some small-molecule activators have been used to assess their potential protective action in mouse models of AD [21-23], while dimethyl fumarate (Tecfidera ${ }^{\circ}$ ) has recently been approved for clinical use for relapsing form of multiple sclerosis [24].

Pyrrolidine dithiocarbamate (PDTC) is a blood-brain barrier permeant metal-chelating compound possessing antioxidant and anti-inflammatory properties. Many studies have reported induction of endogenous antioxidant gene expression and cytoprotective proteins by PDTC [25-29] and inhibition of nuclear factor- $\mathrm{kB}$ (NF$\kappa B)$ [30-33]. The protective function of PDTC in animal models of central nervous system disorders has also been explored in several studies [34-40], while we and others have shown that PDTC is protective in AD mouse models $[41,42]$. The protective mechanism of action of PDTC in AD involves modulation of brain copper concentration, glycogen synthase kinase $3 \beta$ (GSK3 $\beta$ ), and glial glutamate transporters, as well as suppression of NF- $\mathrm{BB}$ signaling. While we have recently shown that PDTC increases the proliferation of neural stem/progenitor cells in a manner similar to that caused by Nrf2 overexpression [43], the involvement of Nrf2 in PDTCmediated effects remains unknown.

The present study aimed to explore the effect of PDTC on Nrf2 induction in normal conditions and in a setting of elevated $A \beta$. Here, we report that (i) Nrf2 is required for the PDTC-mediated enhancement of cellular resistance to oxidative damage, (ii) PDTC-induced Nrf2 activation occurs preferentially in astrocytes, and (iii) PDTC-mediated Nrf2 induction is amplified in the presence of $A \beta$.

\section{Methods}

\section{Primary adult astrocyte culture}

Cortices were isolated from 6- to 8-week-old C57Bl/6J mice and the Nrf2-disrupted C57BL/6JJcl mice generated by Itoh et al. [44] as described previously [45]. Following dissociation, the tissue was suspended in DMEM/F12 (3:1, Gibco) containing $10 \% \mathrm{FBS}$ and $100 \mathrm{U} / \mathrm{mL}$ penicillin- streptomycin (Gibco). The suspension was triturated and centrifuged at $1500 \mathrm{rpm}$ for $5 \mathrm{~min}$ at room temperature. After adding $0.25 \%$ trypsin-EDTA (Gibco), the suspension was incubated at $37{ }^{\circ} \mathrm{C}$ for $30 \mathrm{~min}$. Fresh culture medium was added, and the suspension was centrifuged at $1500 \mathrm{rpm}$ for $5 \mathrm{~min}$. The cells were treated with $27 \%$ Percoll (SigmaAldrich) in culture media, centrifuged at $1500 \mathrm{rpm}$ for $10 \mathrm{~min}$ and washed once with fresh culture media. The cells were plated onto poly-L-lysine coated flasks in DMEM/F12 (3:1) containing $10 \%$ FBS, $100 \mathrm{U} / \mathrm{mL}$ penicillinstreptomycin, and G5 supplement (Gibco). Cells were used between passages 3 and 7. These cultures are $99.8 \%$ GFAPpositive, as determined by immunocytochemistry [45].

\section{Primary neonatal astrocyte culture}

Primary astrocyte cultures were prepared from neonatal mice according to the method of Hamprecht and Löffler [46]. Briefly, as previously described [47], brains removed from newborn C57BL/6J mouse pups were mechanically dissociated by sequential passes through 250 and $135 \mu \mathrm{m}$ nylon mesh, centrifuged at $500 \times g$ for $5 \mathrm{~min}$ before resuspension in DMEM supplemented with $50 \mathrm{U} / \mathrm{mL}$ penicillinstreptomycin and $10 \% \mathrm{FBS}$ and plated at 160,000 cells/ $\mathrm{cm}^{2}$. The medium was renewed every 7 days, and cultures were used between 15 and 21 days in vitro, 1-2 days after medium renewal. Immunocytochemical analysis shows these cultures contain approximately $80 \%$ GFAP-positive astrocytes with the remainder mainly IBA1-positive microglia but no neurons (data not shown).

\section{Primary hippocampal neuron culture}

Hippocampi were dissected from embryonic day 18 mouse fetal brains and prepared as described previously [13]. Following dissociation, the cells were suspended in Neurobasal culture medium supplemented with $2 \%$ B27, $500 \mu \mathrm{M}$ glutamine, $25 \mu \mathrm{M}$ glutamate, and $1 \%$ penicillinstreptomycin (Gibco) and plated on 24- or 48-well culture plates precoated with poly-ornithine $(0.5 \mu \mathrm{g} / \mu \mathrm{L}$, SigmaAldrich) at 400,000 or 200,000 cells/well, respectively. One day after plating, the medium was supplemented with $10 \mu \mathrm{M}$ cytosine $\beta$-D-arabinofuranoside and cells were grown in this media for 3 days prior to changing to media devoid of cytosine $\beta$-D-arabinofuranoside. Five days after plating, one third of the media was changed. Cells were treated at 7 days after harvesting. About $90 \%$ of cells in these cultures are neurons [13].

\section{Primary mixed cortical culture}

Primary mixed cultures of cortical neurons and astrocytes were prepared from embryonic day 14 mouse brains and maintained in neurobasal medium supplemented with $500 \mu \mathrm{M}$ glutamine, $10 \mu \mathrm{g} / \mathrm{mL}$ gentamycin, and $2 \% \mathrm{~B} 27$ as previously described [47]. Cells were used at 8 days in vitro, 2 days after renewal of medium. Neurons account for 
approximately $60-70 \%$ of cells in these cultures, as determined by immunocytochemical staining for MAP-2 (data not shown).

\section{Cell treatments}

PDTC (Sigma-Aldrich) was dissolved in sterile water and used immediately after preparation. The kinase inhibitors 10-DEBC, FPA-124, LY294002, PD198306, PD98059, PI828, SB415286, and SL327 (Tocris) were dissolved in DMSO to $10 \mathrm{mM}$. $\mathrm{A} \beta_{(1-42)}$ was purchased from American Peptide (Sunnyvale, CA) and dissolved to $1 \mathrm{mg} / \mathrm{mL}$ in sterile water. Protein concentration of the peptide was verified by DC protein assay kit (Bio Rad). The soluble peptide was used for experiments immediately after preparation as described [13].

\section{Viability assays}

Cell viability following treatments was assessed by kinetically measuring the release of lactate dehydrogenase (LDH) into the culture medium using an LDH determination kit (Sigma-Aldrich/Roche). MTT reduction was assessed following incubation of cells with $480 \mu \mathrm{M}$ MTT for $1 \mathrm{~h}$ before lysing in DMSO and quantifying absorbance at $560 \mathrm{~nm}$. The data are expressed as percentage of control. For counting purposes, cells were fixed in $4 \%$ paraformaldehyde for $30 \mathrm{~min}$, stained with Hoechst, and enumerated from at least nine fields/treatment.

\section{Immunocytochemistry}

After treatment, cells were fixed with $4 \%$ paraformaldehyde for $20 \mathrm{~min}$ before blocking and permeabilizing in PBS containing $1 \%$ BSA and $0.3 \%$ triton X-100. Cells were subsequently incubated with antibody to Nrf2 (1:1000, Cell Signaling Technology (CST) \#12721), MAP2 (1:1000; Chemicon, Merck Millipore), or GFAP (1:1000; Dako) overnight at $4{ }^{\circ} \mathrm{C}$ before further incubation with AlexaFluor-488, AlexaFluor-568, or AlexaFluor-647 secondary antibodies (1:250) for $1 \mathrm{~h}$ at room temperature. Before mounting onto microscope slides, cells were incubated with $0.5 \mu \mathrm{g} / \mathrm{mL}$ DAPI for $5 \mathrm{~min}$. Cells were imaged with a Zeiss LSM Meta confocal microscope. Nuclear fluorescence intensity of Nrf2 was determined from approximately 500-700 cells per condition using ImageJ software.

\section{Nuclear fractionation}

Following treatment, cells were washed twice with icecold PBS, collected into the PBS and centrifuged at $720 \times g$ for $3 \mathrm{~min}$. Pellets were lysed in lysis buffer (50 mM Tris/ $/ \mathrm{HCl}, 0.5 \%$ triton X-100, $137.5 \mathrm{mM} \mathrm{NaCl}$, $10 \%$ glycerol, $1 \mathrm{mM}$ sodium vanadate, $50 \mathrm{mM}$ sodium fluoride, $10 \mathrm{mM}$ sodium pyrophosphate, $5 \mathrm{mM}$ EDTA, $1 \%$ protease inhibitor cocktail (Sigma-Aldrich), $\mathrm{pH} 7.5$ ) and resultant homogenates centrifuged at $15,000 \times g$ for $15 \mathrm{~min}$. The supernatant was collected as cytosolic fraction before the pellet was rinsed with lysis buffer, re-centrifuged, and resuspended in lysis buffer containing $0.5 \%$ SDS. Homogenates were sonicated before centrifuging at $15,000 \times g$ for $15 \mathrm{~min}$ and the supernatant collected as nuclear fraction. Samples were maintained at $4{ }^{\circ} \mathrm{C}$ throughout the procedure. Protein content was determined by BCA assay (Pierce).

\section{Gel electrophoresis and western blots}

Proteins were harvested with PhosphoSafe buffer (Merck) containing protease inhibitor complete tablet (Complete, Roche Applied Sciences, Mannheim, Germany) or lysis buffer (as above). Proteins were separated on $12 \%$ SDSPAGE Tris-glycine gels. Proteins were transferred to PVDF membrane using Mini Trans-blot electrophoretic transfer cell equipment (Bio Rad) or Novex mini gels (Invitrogen) and then blocked in a solution of $5 \%$ non-fat dry milk in $0.2 \%$ Tween-20/0.01 M PBS for $30 \mathrm{~min}$. For immunodetection of separated proteins, the membranes were incubated overnight at $+4{ }^{\circ} \mathrm{C}$ with the following primary antibodies: HO-1 (Stressgen or CST), NQO1 (Abcam), Nrf2 (Santa Cruz Biotechnology or CST), Keap1 (CST), phospho-Akt (Ser473; CST), phospho-ERK1/2 (Thr202/Tyr204; CST), phospho-GSK3 $\alpha / \beta$ (Ser21/9; CST), and $\beta$-actin (CST), GAPDH (CST), or histone H3 (CST) for loading controls. For detection, the membranes were incubated with HRP-conjugated Ig anti-rabbit, anti-mouse, or anti-goat secondary antibodies (1:5000; CST) for $2 \mathrm{~h}$, developed using enhanced chemiluminescence (GE Healthcare ECL Advance Chemiluminescence kit) and imaged on a Fujifilm LAS3000 Imager (Berthold).

\section{Quantitative real-time PCR}

RNA was isolated with RiboPure RNA kit (Life Technologies), and $500 \mathrm{ng}$ of total RNA was used for cDNA synthesis using random hexamer primers (Promega, Madison, WI) and M-MuLV reverse transcriptase (New England Biolabs, Ipswich, MA) or Maxima reverse transcriptase (Thermo Scientific). The relative expression levels of mRNA encoding HO-1, GCLM, GCLC, NQO1, and Nrf2 were measured according to manufacturer's protocol by quantitative RT-PCR (ABI PRISM 7700 Sequence detector, Applied Biosystems, Foster City, CA) using specific Assays-On-Demand target mixes (Applied Biosystems/Invitrogen). The expression levels were normalized to $\beta$-macroglobulin or $\beta$-actin and are presented as fold change in the expression over control.

\section{Glutamate-cysteine ligase activity assay}

GCL activity was determined according to a modified method of White et al. [48]. Following treatment, cells were washed twice with ice-cold PBS before hypotonic lysis in $20 \mathrm{mM} \mathrm{KP}$ for $10 \mathrm{~min}$ on ice. Cells were 
quantitatively collected and centrifuged at $15,000 \times g$ for $10 \mathrm{~min}$ before $50 \mu \mathrm{L}$ samples of supernatant were combined with $50 \mu \mathrm{L} 400 \mathrm{mM}$ Tris $\mathrm{pH}$ 7.4, $20 \mathrm{mML}$-glutamic acid, $2 \mathrm{mM}$ EDTA, $20 \mathrm{mM}$ sodium borate, $2 \mathrm{mM}$ L-serine, $40 \mathrm{mM} \mathrm{MgCl}_{2}$, and $40 \mathrm{mM} \mathrm{ATP}$. For detection of basal glutathione and $\gamma$-glutamylcysteine content, duplicate $50 \mu \mathrm{L}$ samples were combined with the same plus addition of $2 \mathrm{mM} \mathrm{L}$-buthionine sulfoximine to inhibit GCL activity. Samples were warmed to $37^{\circ} \mathrm{C}$, and the GCL reaction was initiated by addition of $2 \mathrm{mML}$-cysteine in $20 \mathrm{mM}$ Tris $\mathrm{pH}$ 7.4, $1 \mathrm{mM}$ EDTA, $250 \mathrm{mM}$ sucrose, $20 \mathrm{mM}$ sodium borate, and $2 \mathrm{mM} \mathrm{L}$-serine. After incubation for $1 \mathrm{~h}$ at $37{ }^{\circ} \mathrm{C}$, the GCL reaction was halted by addition of $50 \mu \mathrm{L}$ ice-cold $200 \mathrm{mM}$ sulfosalicylic acid. Aliquots $(20 \mu \mathrm{L})$ were combined with reaction mix to final concentration of $1 \mathrm{mM}$ 2,3-naphthalenedicarboxyaldehyde in $50 \mathrm{mM} \mathrm{NaOH}$ and $35 \mathrm{mM}$ Tris for $30 \mathrm{~min}$ before fluorescence intensity was determined at $470 \mathrm{ex} / 530 \mathrm{em}$ on an EnSpire multimode reader (PerkinElmer). Glutathione was used as standards. The difference between values in the absence and presence of L-buthionine sulfoximine is proportional to GCL activity, given as nmol $\gamma$-glutamylcysteine $(\gamma \mathrm{GC})$ generated per minute per milligram protein.

\section{Glutathione assay}

Total glutathione content was determined according to the method of Tietze [49] as described previously [50]. For determination of cellular glutathione, $10 \mu \mathrm{L}$ samples of cell lysates in $1 \%$ sulfosalicylic acid were analyzed. For media analysis, one part medium was combined with one part water and two parts $1 \%$ sulfosalicylic acid, and $20 \mu \mathrm{L}$ of this was analyzed. Following addition of reaction mix to a final concentration of $200 \mu \mathrm{M}$ NAPDH, $150 \mu \mathrm{M} 5,5$ dithiobis-(2-nitrobenzoic acid), and $0.1 \mathrm{U}$ glutathione reductase (Sigma-Aldrich) in $50 \mathrm{mM} \mathrm{NaP} \mathrm{i}_{\mathrm{i}}$ buffer $\mathrm{pH} 7.5$ containing $0.5 \mathrm{mM}$ EDTA, the rate of thionitrobenzoate production was followed spectrophotometrically at $405 \mathrm{~nm}$.

\section{Animal experiments}

Starting from the age of 6 months, C57BL/6J wild-type (WT) mice were treated with PDTC $(20 \mathrm{mg} / \mathrm{kg} /$ day $)$ in drinking water for 9 months as previously described [41] ( $n=6-8 /$ group). A second cohort of mice was treated for 2 weeks at a dose of $75 \mathrm{mg} / \mathrm{kg} /$ day. The mice were deeply anesthetized with avertin and transcardially perfused with heparinized saline after which the brain was dissected and snap-frozen in liquid nitrogen. Brain tissue was also collected from Nrf2-deficient C57BL/6JJcl mice generated by Itoh et al. [44]. All animal work was approved by the National Animal Experiment Board of Finland (license number ESAVI-2011-000855) and followed the guidelines of the Council of Europe Legislation and Regulation for Animal Protection.

\section{Immunohistochemistry}

Pentobarbital-anesthetized mice were transcardially perfused with heparinized saline. The brains were immersion-fixed with $4 \%$ paraformaldehyde for $21 \mathrm{~h}$ and cryoprotected in $30 \%$ sucrose for $48 \mathrm{~h}$. The brains were frozen on liquid nitrogen and cut to $20-\mu \mathrm{m}$-thick cryosections. Sections were immunostained with HO-1 (Stressgen or CST) and GFAP (DakoCytomation, Glostrup, Denmark) overnight at room temperature. Primary antibody binding was detected by using Alexa Fluor 568-conjugated secondary antibody for HO-1 and Alexa Fluor 488-conjugated secondary antibody for GFAP (Invitrogen, Eugene, OR). The hippocampal dentate gyrus area from four to six sections in 200- $\mu \mathrm{m}$ intervals through the hippocampi were evaluated per animal. For quantification, the sections were imaged with an Olympus AX70 microscope (Olympus, Melville, NY) with an attached digital camera (Color View 12 or F-View; Soft Imaging System, Munster, Germany).

\section{Ferrous oxidation-xylenol orange (FOX) assay}

Hippocampal tissues were sonicated in 90 \% cold acetone solution and centrifuged at room temperature at $10,000 \times g$ for $10 \mathrm{~min}$. Hydroperoxides were quantified from the supernatant based on detection of hydroperoxidemediated oxidation of ferrous to ferric ion in the presence of xylenol orange [51] using hydrogen peroxide standards.

\section{Determination of brain copper content}

The copper content of cerebella isolated from mice treated with PDTC for 2 weeks were measured by ICPMS after freeze-drying and acid-digestion in nitric acid and hydrogen peroxide. The copper concentrations were determined with ICP-MS using external calibration and internal standard correction.

\section{Statistical analyses}

The data were analyzed by using $t$ test or ANOVA followed by Dunnett post hoc tests comparing to control condition in GraphPad Prism software, and statistical significance was assumed if $p<0.05$. Unless otherwise mentioned, data are expressed as means \pm SD.

\section{Results}

PDTC induces nuclear translocation of Nrf2 in astrocytes

Primary neurons and astrocytes were harvested from mouse brain to assess the ability of PDTC to induce the Nrf2 pathway. When used at $1-$ to $100-\mu \mathrm{M}$ concentrations, PDTC did not cause astrocytic cell death as measured by the LDH release or MTT assay after $24 \mathrm{~h}$ treatment (Additional file 1: Figure S1A-B). PDTC did not cause death of hippocampal neurons when used at 1- to 50- $\mu \mathrm{M}$ concentrations (Additional file 1: Figure S1C). 
Nrf2 translocation into nuclei was first assessed by immunocytochemical staining of primary neonatal astrocytes treated with PDTC for $4 \mathrm{~h}$ (Fig. 1a). PDTC treatment induced a significant, tenfold increase in nuclear Nrf2 expression in astrocytes (Fig. 1b). A slight, 1.5-fold increase in nuclear Nrf2 was observed in hippocampal neurons treated with PDTC (Fig. 1c). Strong nuclear Nrf2 induction in mixed cortical cultures was restricted to MAP2-negative GFAP-positive cells (Fig. 1d). The specificity of the Nrf2 antibody and lack of PDTC effect in Nrf2-deficient cells was confirmed by absence of immunostaining in $\mathrm{Nrf2}^{-1-}$ astrocytes (Additional file 2: Figure S2). Nrf2 translocation was further confirmed by western blot of neonatal astrocytes after nuclear fractionation (Fig. 1e). PDTC induced a dose-dependent increase in the levels of nuclear Nrf2 in astrocytes (Fig. 1f).

\section{PDTC induces Nrf2 target genes in astrocytes but not neurons}

Given that PDTC was a strong inducer of Nrf2 nuclear translocation, we next assessed the potential of PDTC to induce the expression of Nrf2 target genes. A 24-h treatment with PDTC induced a dose-dependent increase in Nrf2 target genes in adult astrocytes. HO-1 (Fig. 2a) and GCLM (Fig. 2b) mRNA expression levels were significantly elevated in astrocytes treated with 1 and $10 \mu \mathrm{M}$ PDTC but

\section{A}

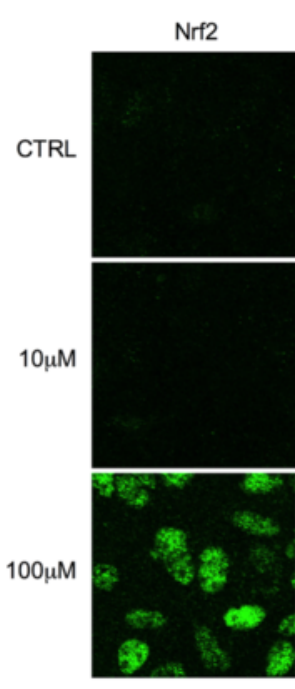

D

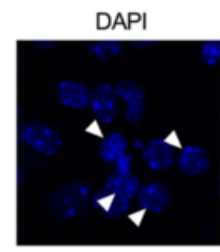

E

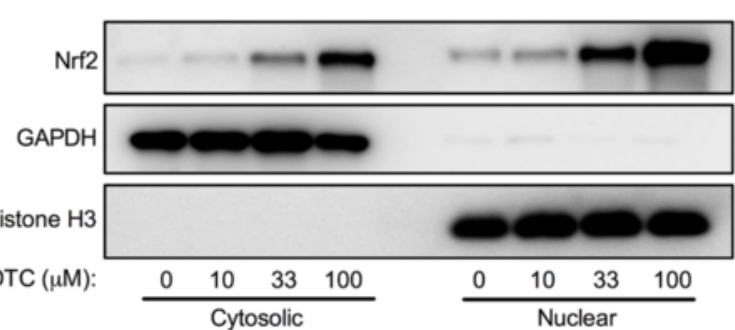

$\mathrm{Nrf2}$

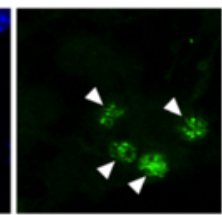

MAP2

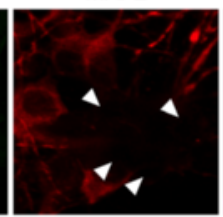

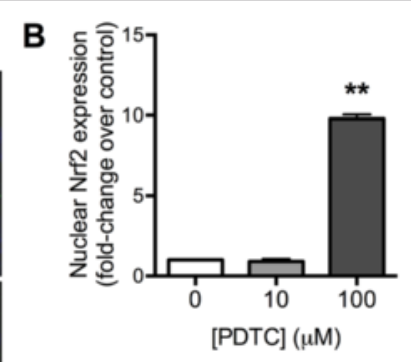
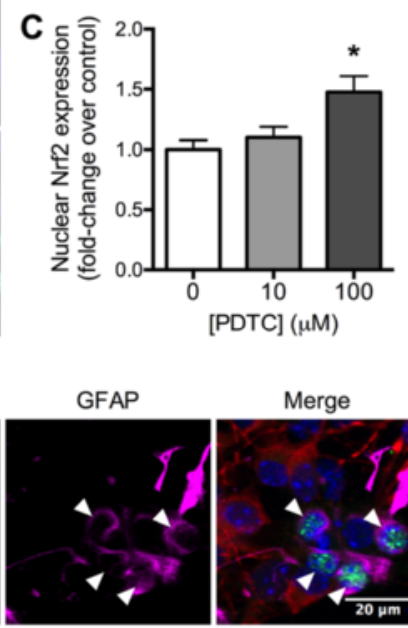

Merge
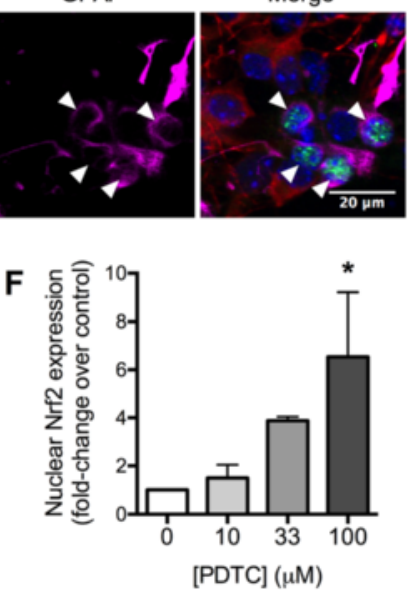

Fig. 1 PDTC-induced translocation of astrocytic Nrf2. a Representative Nrf2 immunostaining images of primary neonatal astrocytes treated with 10 or 100 M PDTC for 4 h. Right panels are merged images of Nrf2 (left panels) and the nuclear marker DAPI (center panels). b Quantification of nuclear Nrf2 immunostaining in astrocytes expressed as fold change over control \pm SD. c Quantification of nuclear Nrf2 immunoreactivity in hippocampal neurons treated with PDTC for $4 \mathrm{~h}$. Data are expressed as fold change over control cells \pm SD. $\mathbf{d}$ Representative immunostaining of mixed cortical cultures treated with PDTC for 4 h, co-stained for DAPI, Nrf2, the neuronal marker MAP2 and astrocyte marker GFAP. Arrowheads indicate MAP2-negative GFAPpositive cells with strongly increased nuclear Nrf2. e A representative immunoblot with antibodies against Nrf2, GAPDH (cytosolic marker), and histone H3 (nuclear marker) with neonatal astrocyte samples treated with PDTC for 4 h. f Quantification of nuclear Nrf2 protein levels after 4 h PDTC treatment of astrocytes. Data are expressed as fold change over control cells normalized to histone H3 \pm SD ${ }^{*} p<0.05 ;{ }^{* *} p<0.001$. Scale bar $=20 \quad m$ 
not in hippocampal neurons. PDTC did not increase the mRNA expression levels of Nrf2, NQO1, or GCLC in either cell type (data not shown). Protein expression of HO-1 and the negative regulator of Nrf2, Keap1, was assessed by western blot in neonatal astrocytes treated with PDTC for $4 \mathrm{~h}$ (Fig. 2c). Keap1 expression decreased while HO-1 was strongly elevated (Fig. 2d, e).

\section{PDTC treatment increases GCL activity and glutathione levels in astrocytes}

Because Nrf2 induction is known to increase glutathione biosynthesis in astrocytes, we investigated the potential of PDTC in this process. A 24-h PDTC treatment significantly increased GCL activity in neonatal astrocytes (Fig. 2f). Furthermore, cellular glutathione (GSH) levels and the release of GSH into the media were increased by PDTC (Fig. 2g, h), indicating that PDTC has potent antioxidant actions through GSH upregulation.

\section{Nrf2 is more readily induced in adult astrocytes as compared to neonatal astrocytes}

Significant up-regulation of HO-1 and GCLM occur with as little as $1 \mu \mathrm{M}$ PDTC in adult astrocytes (Fig. 2a, b), whereas $100 \mu \mathrm{M}$ PDTC is required to significantly increase HO-1 expression, GCL activity, and glutathione

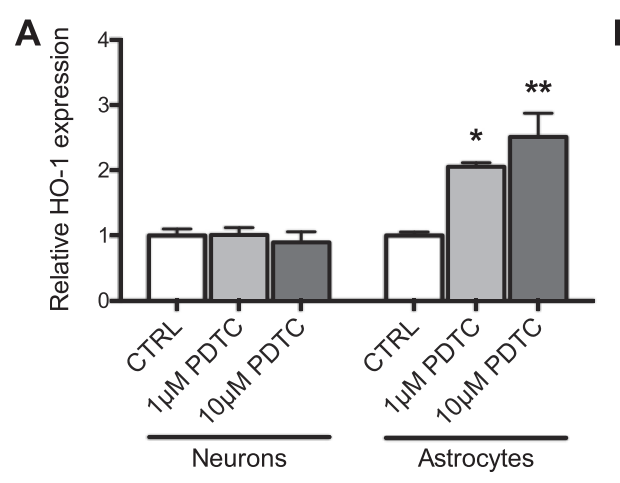

C


D

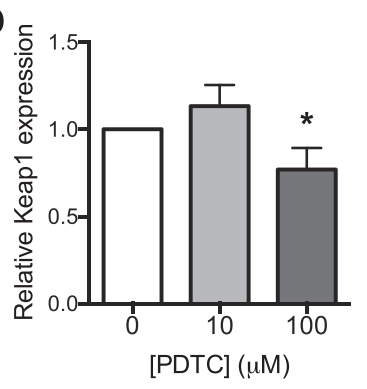

G

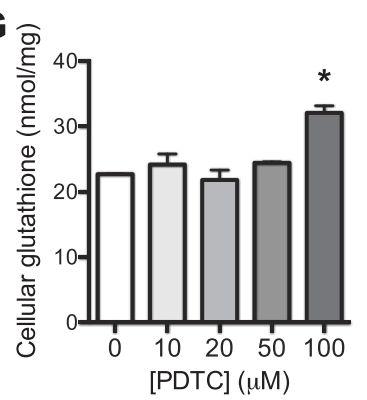



E

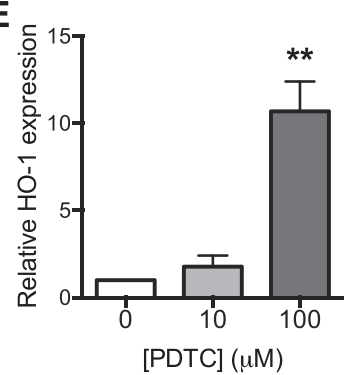

$\mathbf{H}$

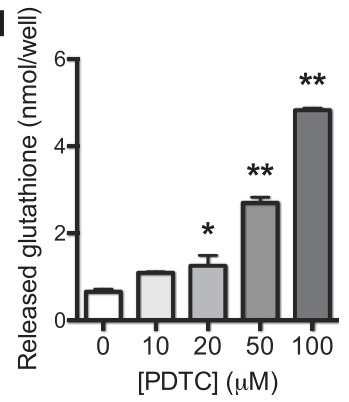

Fig. 2 Effect of PDTC treatment on Nrf2 target genes, GCL activity, and glutathione content. a HO-1 and $\mathbf{b}$ GCLM mRNA expression levels measured by quantitative RT-PCR from primary adult astrocyte cultures and hippocampal neuron cultures after $24 \mathrm{~h}$ PDTC treatment. The mRNA expression levels are presented as mean relative expression normalized to $\beta$-actin \pm SD. $\mathbf{c}$ Representative immunoblots with antibodies against Keap1, HO-1, and GAPDH from neonatal astrocytes treated with PDTC for $4 \mathrm{~h}$. $\mathbf{d}$ Quantification of Keap1 and e HO-1 protein levels. Data are expressed as fold change over control cells normalized to GAPDH \pm SD. f Neonatal astrocytes were treated with PDTC for 24 h, before GCL activity was determined. Data are expressed as mean nanomole GC produced per minute per milligram protein \pm SD. $\mathbf{g}$ The cellular glutathione content was measured after $24 \mathrm{~h}$ PDTC treatment of neonatal astrocytes and normalized to cellular protein content \pm SD. Data are expressed as nanomole glutathione content per milligram protein. $\mathbf{h}$ Glutathione released into the media from neonatal astrocytes was measured $24 \mathrm{~h}$ after PDTC treatment. Data are shown as nanomole of glutathione released into the well \pm SD. ${ }^{*} p<0.05$; ${ }^{*} p<0.001$ relative to corresponding control 
content in neonatal astrocytes (Fig. 2c, e-g). This indicates that astrocytes cultured from adult mice are more sensitive to PDTC than astrocytes cultured from neonatal mice.

Nrf2 induction by PDTC involves kinase phosphorylation Increased phosphorylation of Akt and ERK1/2 and inhibitory phosphorylation of GSK3 $\alpha / \beta$ were increased in PDTC-treated neonatal astrocytes (Fig. 3a-d), consistent with Nrf2 activation. The small-molecule GSK3 inhibitor SB415286 did not alter the PDTC-induced increase in $\mathrm{Nrf} 2, \mathrm{HO}-1$, or GSH export but did significantly increase cellular Nrf2 levels and increase exported glutathione $\sim 1.7$-fold over cells treated in the absence of PDTC (Fig. 3e-h), suggesting the inhibitory phosphorylation of GSK3 induced by PDTC contributes to the activation of Nrf2. Cellular GSH levels were unchanged (data not shown). Inhibition of the ERK-activating mitogen-activated protein kinase kinase (MEK) by SL327, PD198306 or PD98059 did not significantly alter Nrf2 or HO-1 protein levels or GSH export (Additional file 3: Figure S3A-D), nor did inhibition of PI3K by LY294002 or PI828 and Akt by FPA124 or 10DEBC (Additional file 3: Figure S3E-H). These inhibitors did not significantly decrease cellular GSH (data not shown) or significantly alter cellular viability with the exception of FPA124 and PI828, which mildly decreased viability (Additional file 4: Figure S4A-B).
Nrf2 is required for the PDTC-mediated induction of NQO1 and up-regulation of glutathione biosynthesis When compared to WT astrocytes, the PDTC-mediated increases in both cellular and released GSH were significantly reduced in $\mathrm{Nrf}^{-/-}$astrocytes (Fig. 4a, b), indicating that $\mathrm{Nrf} 2$ is central to the GSH-inducing effect of PDTC. Furthermore, PDTC induced astrocytic protein expression of $\mathrm{HO}-1$ and NQO1 after $24 \mathrm{~h}$ treatment (Fig. 4c, e, f). Importantly, NQO1 expression was not induced by PDTC treatment in astrocytes harvested from $\mathrm{Nrf}^{-/-}$mice (Fig. 4d, e). Taken together, these results suggest that Nrf2 is required for PDTC-mediated induction of both glutathione biosynthesis and induction of protective protein expression.

\section{Co-treatment of PDTC with amyloid-beta magnifies Nrf2-ARE induction in astrocytes}

We have earlier shown that PDTC treatment [41] and Nrf2 overexpression [16] are protective in transgenic AD mice. To investigate the influence of an elevated $A \beta$ containing milieu on PDTC-mediated induction of the Nrf2-ARE, a co-treatment approach was applied. Treatment of hippocampal neurons and adult astrocytes with $5 \mu \mathrm{M} \mathrm{A} \beta_{(1-42)}$ alone caused a small increase in the expression of Nrf2-controlled HO-1, but not GCLM, after $24 \mathrm{~h}$ (Fig. 5a, b).

Co-treating cells for $24 \mathrm{~h}$ with $\mathrm{A} \beta$ and PDTC resulted in further substantial increases in astrocytic HO-1 (Fig. 5a), greater than that observed when treated with PDTC alone.

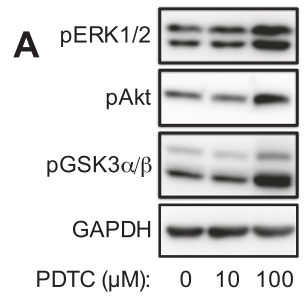

E

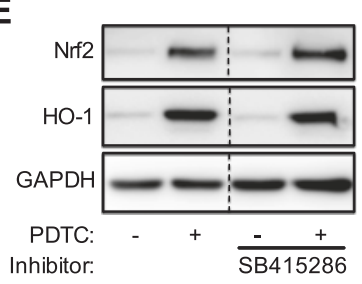

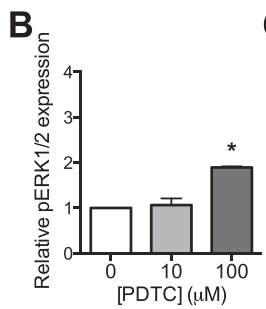

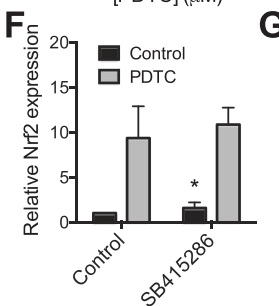

C
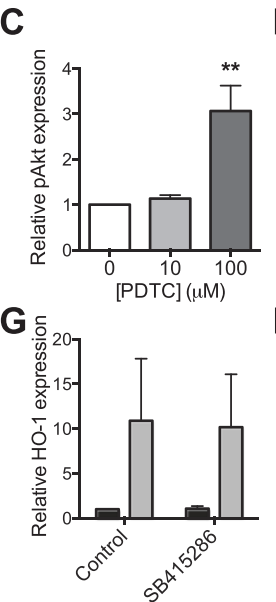

D
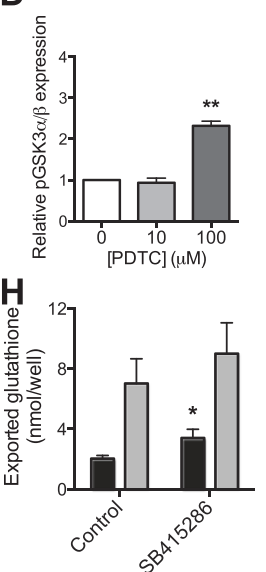

Fig. 3 Involvement of kinases in Nrf2 induction by PDTC. a Representative immunoblots with antibodies against phosphorylated ERK1/2, phosphorylated Akt, phosphorylated GSK3 / $\beta$, and GAPDH in neonatal astrocytes treated with PDTC for 4 h. b Quantification of pERK1/2, c pAkt, and $\mathbf{d}$ pGSK3 / $\beta$ protein levels. Data are expressed as fold change over control cells normalized to GAPDH \pm SD. e Representative immunoblots with antibodies against Nrf2, HO-1, and GAPDH in neonatal astrocytes co-treated for $4 \mathrm{~h}$ with PDTC and SB415286 (GSK3 inhibitor). f Quantification of Nrf2 and $\mathbf{g}$ HO-1 protein expression after $4 \mathrm{~h}$ co-treatment of astrocytes with PDTC and SB415286. Data are expressed as fold change over control cells in absence of inhibitor, normalized to GAPDH \pm SD. $\mathbf{h}$ Exported glutathione after $4 \mathrm{~h}$ PDTC co-treatment of neonatal astrocytes in presence of SB415286. Data expressed as nanomole glutathione released into the medium per well. ${ }^{*} p<0.05$; ${ }^{* *} p<0.01$ relative to corresponding control 


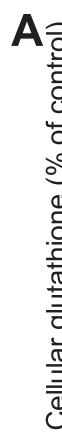

Aิㅡ
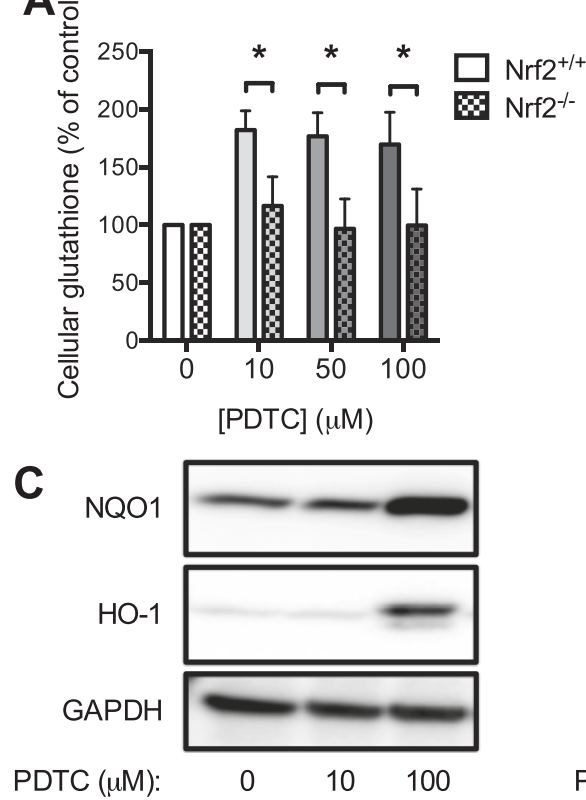

\section{E}

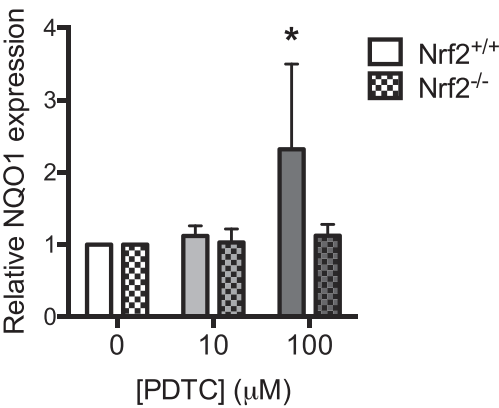

B 흐
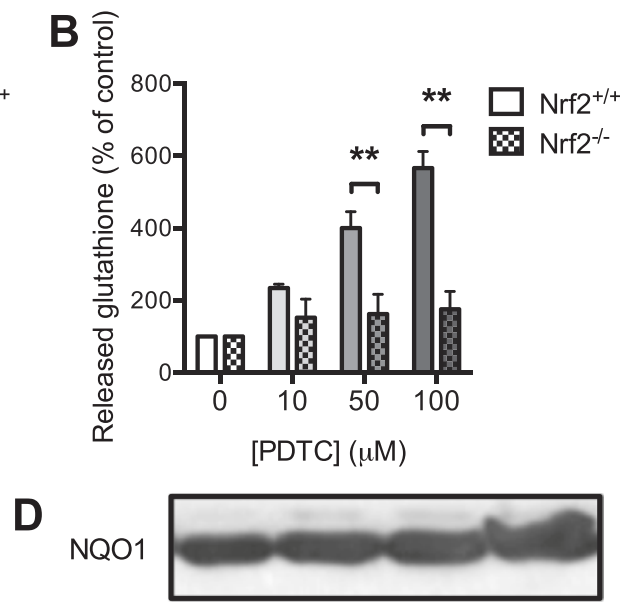

HO-1

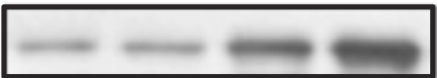

$\beta$-actin

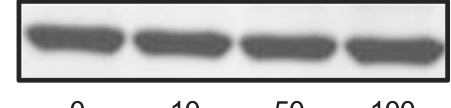

F

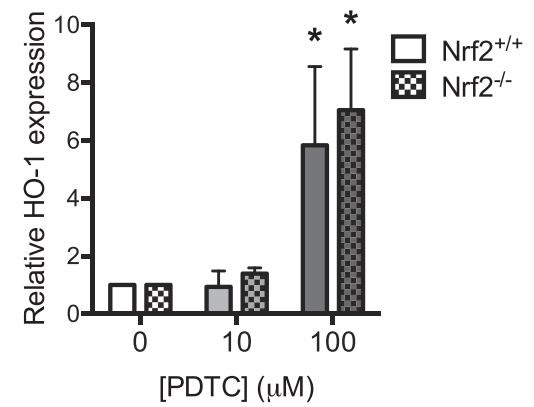

Fig. 4 Absence of Nrf2 induction in Nrf2-deficient astrocytes. a Cellular and $\mathbf{b}$ released glutathione were determined from WT and Nrf2-deficient adult astrocytes treated with PDTC for $24 \mathrm{~h}$. Data are expressed as percentage of control cells \pm SD. c Representative immunoblots with antibodies against NQO1, HO-1, and GAPDH from WT astrocyte samples or $\mathbf{d}$ NQO1, HO-1, and $\beta$-actin from Nrf2 ${ }^{-1-}$ astrocyte samples treated with PDTC for $24 \mathrm{~h}$. e Quantification of NQO1 and $\mathbf{f}$ HO-1 protein expression in WT ( $\left.\mathrm{Nrf}^{+/+}\right)$and Nrf2-deficient $\left(\mathrm{Nrf2}^{-/-}\right)$astrocytes treated with PDTC for $24 \mathrm{~h}$. Data are expressed as fold change over control normalized to GAPDH or $\beta$-actin \pm SD. ${ }^{*} p<0.05$; ${ }^{* *} p<0.001$ relative to corresponding control
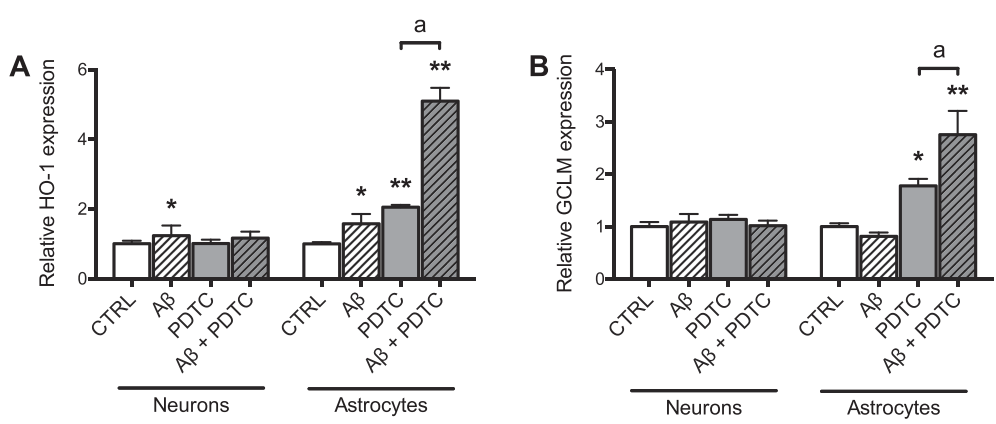

Fig. 5 Effect of PDTC and A Co-treatment on Nrf2 target genes in primary astrocytes and neurons. a HO-1 and $\mathbf{b}$ GCLM mRNA expression levels were measured by quantitative RT-PCR from primary adult astrocyte cultures and hippocampal neuron cultures after $24 \mathrm{~h}$ treatment with $5 \mathrm{M}$ $A \beta_{(1-42)}$ with or without co-treatment with 1 M PDTC. The mRNA expression levels are presented as mean relative expression normalized to $\beta$-actin \pm SD. ${ }^{*} p<0.05 ;{ }^{* *} p<0.001$ relative to corresponding control; ${ }^{a} p<0.001$ relative to PDTC condition 
A


Fig. 6 In vivo effects of PDTC on HO-1 expression, copper content and lipid peroxidation. a Representative immunostaining images of brain sections from WT mice treated with PDTC for 9 months with or without PDTC at a dose of 20 mg/kg/day. HO-1, GFAP, and nuclear DAPI were imaged from the hippocampal dentate gyrus. $\mathbf{b}$ The percentage of glial cells expressing $\mathrm{HO}-1$ in the hippocampal dentate gyrus was calculated from five WT mice receiving PDTC for 9 months at a dose of $20 \mathrm{mg} / \mathrm{kg} /$ day and five vehicle-treated animals. Data are shown as percentage of HO-1 positive cells \pm SD. c Cerebellar copper concentrations were measured from WT mice treated with PDTC for 2 weeks at a dose of 75 mg/ $/ \mathrm{kg} /$ day by ICP-MS and are shown normalized to mass of the tissue \pm SD. $\mathbf{d}$ Lipid peroxidation in hippocampi of WT mice treated for 9 months with or without PDTC at a dose of $20 \mathrm{mg} / \mathrm{kg} / \mathrm{day}$ and in e WT and $\mathrm{Nrf2}^{-1-}$ hippocampi were measured by the FOX assay. Data are expressed as $\mathrm{M}$ hydroperoxides per milligram protein $\pm \mathrm{SD}$. ${ }^{*} p<0.05 ;{ }^{* *} p<0.01$ 
HO-1 levels in neurons remained unchanged (Fig. 5a). While astrocytic NQO1 expression was not significantly increased by $A \beta$ treatment (data not shown), a similar PDTC-mediated potentiation effect specifically in astrocytes was observed for GCLM mRNA expression levels (Fig. 5b), over that induced by PDTC alone.

Taken together, these results indicate that while the presence of $A \beta$ slightly induces the expression of Nrf2 target genes, robust induction of the protective pathway is only achieved with co-treatment of PDTC and A $\beta_{(1-42)}$, and this induction appears to be specifically restricted to astrocytes, not neurons.

\section{PDTC increases glial HO-1 expression and brain copper content in vivo}

To assess the effect of PDTC treatment on expression of Nrf2 and target genes in the brain, we first measured mRNA expression levels of NQO1, HO-1, and Nrf2 and protein expression of Nrf2 and NQO1 in the hippocampi of WT mice treated with PDTC for 2 weeks at $75 \mathrm{mg} / \mathrm{kg} /$ day and in mice treated for 9 months at a dose of $20 \mathrm{mg} / \mathrm{kg} /$ day. PDTC treatment did not induce Nrf2related genes (Additional file 5: Figure S5A-C) or protein expression of $\mathrm{Nrf} 2$ and $\mathrm{NQO} 1$ in the hippocampal tissue homogenates (Additional file 5: Figure S5D-F). To exclude the possibility that the lack of effect was due to PDTC not entering the brain, copper levels were assessed in the brains of PDTC-treated mice. As we have shown earlier [41], PDTC treatment caused a significant increase in copper levels in the cerebella (Fig. 6c), indicating that orally administered PDTC penetrated the brain but failed to induce Nrf2-controled gene and protein expression when assessed from tissue homogenates.

To assess the in vivo effect of oral PDTC administration in more depth and to determine the cell-specific effects of PDTC, we next quantified the protein expression of HO-1 in the hippocampal dentate gyrus of mice treated with PDTC for 9 months at a dose of $20 \mathrm{mg} / \mathrm{kg} /$ day. The expression of glial $\mathrm{HO}-1$ was increased in PDTC-treated animals in the hippocampal dentate gyrus (Fig. 6a, b). This suggests that in contrast to the lack of PDTC effect in whole tissue homogenates, significant induction of the Nrf2 target gene HO-1 can be achieved in specific cell populations.

\section{PDTC treatment enhances resistance to lipid} peroxidation, which is increased in Nrf2 deficiency in vivo To assess the potential of PDTC in reducing lipid peroxidation, 6-month-old WT mice were treated orally with PDTC for 9 months at a dose of $20 \mathrm{mg} / \mathrm{kg} /$ day according to [41]. As assessed by the FOX assay, oral PDTC treatment reduced the amount of hippocampal hydroperoxides by $62 \%$ (Fig. 6d), thus providing further evidence that PDTC enhances cellular resistance to oxidative damage. Hydroperoxides were increased by $47 \%$ in the $\mathrm{Nrf2}^{-1-}$ hippocampi when compared to WT controls (Fig. 6e).

\section{Discussion}

The crucial function of the Nrf2 pathway in central nervous system disorders is demonstrated by in vivo studies where Nrf2 induction is associated with improvements in behavior and functional outcomes, and lack of Nrf2 is associated with worsened outcome or reduced neuroprotection [52-55], including AD [15]. Correspondingly, Nrf2 appears to be suppressed in the hippocampi of AD patients [12]. Hence, Nrf2 is emerging as an important potential therapeutic target. In recent years, a variety of small-molecule activators of the Nrf2-pathway have been described. These represent an important pharmacological means to control Nrf2 activation. The present study identifies PDTC as a novel inducer of the Nrf2 pathway specifically in astrocytes. This study also finds that further augmentation of Nrf2 induction by PDTC occurs in the presence of $A \beta$ and demonstrates the critical requirement of Nrf2 for the PDTC-mediated enhancement of cellular resistance to oxidative damage.

While we have earlier shown that induction of neuronal Nrf2 is protective in AD models $[13,16]$, it is generally considered that Nrf2 induction occurs primarily in astrocytes and that this induction confers protection upon neurons [10, 56-59]. For example, Nrf2-mediated glutathione release from astrocytes protects neurons [59]. Indeed, a recent study showed that Nrf2 expression is specifically repressed in maturing neurons [60]. However, astrocytic Nrf2 activation can be regulated by neuronal activity: increased neuronal synaptic activity and neurotransmitter release stimulates Nrf2 induction in co-cultured astrocytes but does not alter Nrf2 signaling when neurons are cultured alone, suggesting a critical interplay between neurons and astrocytes in the protective induction of Nrf2 signaling [61]. The results of the current study are entirely consistent with these investigations, whereby robust induction of Nrf2 was only evident in astrocytes, and all but absent in neurons including when cultured with astrocytes. These results indicate that astrocytes are more sensitive to PDTC-mediated induction of the Nrf2-ARE pathway than neurons. Furthermore, Nrf2 induction was more readily induced by PDTC in astrocytes cultured from adult mice as compared to neonatal mice. This is in line with our previous findings that adult astrocytes exhibit greater alterations in gene expression than neonatal astrocytes [62]. The PDTC-conferred enhancement of protective antioxidative mechanisms occurs specifically via activation of Nrf2 signaling, as evidenced by the absence of antioxidant induction in Nrf2-deficient astrocytes. 
The mechanism via which PDTC induces the Nrf2 response likely involves multiple mechanisms, including decreased degradation, altered biometal homeostasis, and potential interplay with NF-kB. These will now be considered. Firstly, PDTC is a well-known inhibitor of the pro-inflammatory transcription factor NF- $\mathrm{kB}$. However, there is much evidence for complex crosstalk between Nrf2 and NF- $\mathrm{kB}$. Nrf2 can directly and indirectly suppress NF- $\mathrm{B}$ signaling, whereas NF- $\mathrm{kB}$ can both amplify and diminish Nrf2 signaling $[63,64]$. NF- $\kappa B$ can decrease Nrf2 binding to DNA by competing for coactivators and promoting a co-repressor [65]. Conversely, NF- $\mathrm{kB}$ can enhance Nrf2 signaling by promoting Nrf2 transcription [63]. It is unclear whether PDTC promotes Nrf2 signaling via inhibition of NF-kB or whether the well-known NF- $\mathrm{BB}$ inhibitory effects of PDTC are at least in part due to Nrf2 activation. Clearly, further studies are required to delineate the relationship between NF- $\mathrm{KB}$ inhibition and Nrf2 induction by PDTC.

The slight increase in cytosolic Nrf2 in addition to increased nuclear Nrf2 suggests that PDTC may stimulate de novo synthesis of Nrf2. Decreased cytosolic degradation is also likely to contribute to the observed elevations in Nrf2. Keap1 is a negative regulator of Nrf2 that promotes cytosolic degradation of Nrf2 [8]. PDTC treatment decreased Keap1 levels, likely reducing Nrf2 degradation and promoting Nrf2 accumulation. In addition, Nrf2 degradation may be reduced by GSK3 $\beta$ inhibition. GSK3 $\beta$ is a kinase that modulates activity of Nrf2-ARE signaling by promoting Keap1-independent Nrf2 degradation $[66,67]$. Direct inhibition of GSK3 $\beta$ results in nuclear accumulation of Nrf2, indicating that GSK3 $\beta$ is a fundamental element of Nrf2-ARE regulation after oxidative injury $[68,69]$. It is known that PDTC exerts its protective effects via reduction of activated GSK3 $\beta$ signaling in $\mathrm{AD}$ [41] and in neonatal hypoxia-ischemia [34]. In agreement with previous studies, we found that PDTC also dampens GSK3 $\beta$ activity in primary astrocytes. Direct inhibition of GSK3 $\beta$ also induced Nrf2 in the current study, although to a lesser extent than PDTC. Inhibition of kinases upstream of GSK3 $\beta$ including MAPK and PI3K/Akt failed to influence Nrf2 induction by PDTC, although this is likely due to redundancy within the kinase pathways. Taken together, it seems that GSK3 $\beta$ is implicated in PDTC-mediated Nrf2 induction. As the activity of GSK3 $\beta$ is known to be influenced by metals [70, 71] and PDTC is reported to bind metals and transport them inside cells, the observed effects could also be related to the metal-chelating property of PDTC [72, 73].

Copper is a trace element that is essential for cellular function. Disturbances in copper homeostasis are detrimental and lead to disease $[74,75]$. We show here that a 2-week treatment of mice with PDTC results in an increased copper concentration in the brain. As copper is known to induce the ERK [76] and Akt pathways [77], we hypothesize that the PDTC-mediated increase in intracellular copper could trigger the phosphorylation of ERK and Akt, leading to reduced GSK3 $\beta$ activity (increased inhibitory phosphorylation) [78]. In support of our hypothesis, it has been shown that copper exposure induces nuclear accumulation of Nrf2 and induces protective Nrf2 signaling [79], which is blocked in Nrf2deficient cells [80]. It is of interest to note that Keap1, the stress sensor and negative regulator of Nrf2, quantifies cellular stress by monitoring intracellular levels of metals such as zinc [81]. Therefore, it seems plausible that PDTC-mediated metal transport is responsible for the observed induction of the Nrf2 signaling in this study. Further studies are clearly required to thoroughly assess the interplay between metal homeostasis and Nrf2.

Our findings on the inhibition of GSK3 $\beta$ by PDTC are particularly interesting in the context of $\mathrm{AD}$, where GSK3 $\beta$ not only phosphorylates tau protein [82] but also affects the expression of $\mathrm{A} \beta$ degrading enzymes [83]. The interplay between $A \beta$ and Nrf 2 is highlighted by our finding that treatment of cells with $A \beta$ resulted in increased expression of the Nrf2 target gene HO- 1 in astrocytes, in line with previous studies [84] and reported increases in HO-1 expression in the AD brain [85]. Furthermore, the increase in $\mathrm{HO}-1$ expression, and that of Nrf2 target gene GCLM, was significantly augmented in astrocytes co-treated with PDTC and A $\beta$. It should be noted that although HO-1 expression can be regulated by other transcription factors besides Nrf2 [86, 87] and therefore making it possible that HO-1 induction may additionally involve other transcription factors, the induction of GCLM indicates that Nrf2 signaling is induced. These results indicate that while $A \beta$ itself has the potential to slightly induce Nrf2 target gene expression, enhanced up-regulation of the protective pathway by PDTC is achieved in an elevated A $\beta$ environment. These data suggest that an AD-related environment is especially favorable for effective induction of protective Nrf2 signaling by PDTC.

We observed a reduction of hippocampal lipid peroxidation with PDTC treatment in tissue homogenates in vivo, suggesting that a more antioxidative environment has been induced. That we detect elevated hydroperoxides in Nrf2-deficient mice supports the notion that Nrf2 is involved in the decreased lipid peroxidation induced by PDTC. The fact that we did not observe a significant induction of other Nrf2-ARE pathway markers in tissue homogenates in vivo is not completely unexpected given the in vitro data shown in this study: robust PDTC-mediated activation of Nrf2 signaling was only observed in astrocytes. While astrocytes have traditionally been viewed as the most abundant cell type in the 
brain, recent reports demonstrate that in the mouse brain, approximately $35 \%$ of the cells are non-neuronal $[88,89]$. This $35 \%$ includes astrocytes, microglia, oligodendrocytes, and various precursor cells. The homogenized tissue samples used in this study for mRNA and protein expression analyses exclude the possibility of discerning the responses of specific cell types; hence, any astrocyte-specific effects will be masked by the presence of other cell types in the tissue homogenates. Indeed, our immunohistochemical analyses of brain showed $\mathrm{HO}-1$ induction in only certain cell types in vivo, indicating that PDTC exerts cell-specific effects also in the brain. It should be noted that the current study did not assess the potential of PDTC to induce Nrf2-ARE signaling in microglial cells. It is therefore possible that the beneficial effects of PDTC on Nrf2 induction also occur in these cells.

Finally, strong in vitro activation of Nrf2 signaling was observed in the presence of $\mathrm{A} \beta$. As the current study utilized only WT mice for assessing the effects of PDTC on Nrf2-ARE induction, it can be speculated that PDTC may also more strongly induce Nrf2-ARE signaling in vivo if $A \beta$ is present. Given that the Nrf2 pathway is impaired in $\mathrm{AD}$ mice and in the brains of AD patients [12, 15], further studies are needed to assess the contribution of $\mathrm{A} \beta$ to PDTC-induced Nrf2 activation in vivo.

\section{Conclusions}

In this study, we have identified a novel function of the metal chelator PDTC: the activation of Nrf2 signaling in astrocytes. Furthermore, activation of Nrf2 was augmented in the presence of $A \beta$, and PDTC decreased brain lipid peroxidation. These effects may contribute to the neuroprotection we and others have observed for PDTC in models of $\mathrm{AD}[41,42]$. The identification of safe, welltolerated molecules that cross the blood-brain barrier to activate the Nrf2-ARE pathway is important, as these may have a valuable role in protecting the brain from oxidative stress associated with neurodegenerative diseases.

\section{Additional files}

Additional file 1: Figure S1. Effect of PDTC treatment on viability of astrocytes and hippocampal neurons. (A) Primary cultures of neonatal astrocytes were treated with increasing concentrations of PDTC for $24 \mathrm{~h}$, after which cell viability was measured by LDH release and (B) MTT reduction assays. (C) Hippocampal neuron survival following 24-h PDTC treatment was measured by manual counting of viable cells/all cells following Hoechst staining. Data are expressed as mean \% of viable cells \pm SD and normalized to control cells in (B) and (C). ${ }^{* *} p<0.001$ relative to corresponding control.

Additional file 2: Figure S2. Absence of Nrf2 immunostaining in $\mathrm{Nrf2}^{-/-}$astrocytes. Representative Nrf2 immunostaining images of primary $\mathrm{Nrf2}^{-/-}$astrocytes treated with $100 \mathrm{M}$ PDTC for $4 \mathrm{~h}$. DAPI staining was carried out to visualize nuclei. Scale bar $=40 \mathrm{~m}$.
Additional file 3: Figure S3. Inhibition of kinases does not alter Nrf2 induction by PDTC. (A,E) Representative immunoblots with antibodies against $\mathrm{Nrf2}, \mathrm{HO}-1$, and GAPDH in primary neonatal astrocytes co-treated for $4 \mathrm{~h}$ with PDTC and (A) SL327 or PD198306 (MEK inhibitors), or (E) LY294002 (PI3K inhibitor) or FPA124 (Akt inhibitor). (B,F) Quantification of $\mathrm{Nrf} 2$ and $(\mathrm{C}, \mathrm{G}) \mathrm{HO}-1$ protein expression after $4 \mathrm{~h}$ co-treatment of astrocytes with PDTC and indicated inhibitors. Data are expressed as fold change over control cells in absence of inhibitors, normalized to GAPDH \pm SD. $(\mathrm{D}, \mathrm{H})$ Exported glutathione after $4 \mathrm{~h}$ PDTC co-treatment of neonatal astrocytes in presence of (D) SL327 or PD98059 (MEK inhibitors), or (H) LY294002 or PI828 (PI3K inhibitors), FPA124 or 10-DEBC (Akt inhibitors). Data expressed as nanomole glutathione released into the medium per well.

Additional file 4: Figure S4. Effect of kinase inhibitors on viability of astrocytes. (A) Cell viability was measured by LDH release and (B) MTT reduction in primary neonatal astrocytes co-treated with PDTC and $10 \mathrm{M}$ indicated inhibitors for $4 \mathrm{~h}$. LDH release expressed as mean percentage of initial total cellular LDH activity \pm SD. MTT reduction expressed as mean percentage of viable cells \pm SD normalized to control cells. ${ }^{*} p<0.05$ relative to corresponding control cells; ${ }^{a} p<0.05$ relative to corresponding treatment without PDTC.

Additional file 5: Figure S5. Expression of Nrf2-pathway related genes and proteins in mouse hippocampi following PDTC treatment. WT mice were treated with PDTC in the drinking water at a dose of $75 \mathrm{mg} / \mathrm{kg} /$ day for 2 weeks, or for 9 months at a dose of $20 \mathrm{mg} / \mathrm{kg} /$ day. (A) $\mathrm{HO}-1$, (B) NQO1, and (C) Nrf2 mRNA expression levels were

measured by quantitative RT-PCR in hippocampal samples and are presented as mean relative expression normalized to $\beta$-actin \pm SD. (D) Representative immunoblots with antibodies against Nrf2, NQO1, and $\beta$-actin with hippocampal samples from mice treated 2 weeks with PDTC at a dose of $75 \mathrm{mg} / \mathrm{kg} /$ day. (E) Quantification of hippocampal Nrf2 protein levels after PDTC treatment of mice. Data are expressed as fold change over control cells normalized to $\beta$-actin \pm SD. (F) Quantification of hippocampal NQO1 protein levels after PDTC treatment of mice. Data are expressed as fold change over control cells normalized to $\beta$-actin \pm SD.

\section{Abbreviations}

AD: Alzheimer's disease; ARE: antioxidant response element; A $\beta$ : amyloidbeta; CST: Cell Signaling Technology; GCL: glutamate-cysteine ligase;

GCLC: glutamate-cysteine ligase catalytic subunit; GCLM: glutamate-cysteine ligase modifier subunit; GSH: glutathione; GSK3: glycogen synthase kinase 3; HO-1: heme oxygenase-1; LDH: lactate dehydrogenase; MEK: mitogenactivated protein kinase kinase; NF-KB: nuclear factor-KB; NQO1: NAD(P)H:quinone oxidoreductase-1; Nrf2: nuclear factor erythroid 2related factor 2; PDTC: pyrrolidine dithiocarbamate; ROS: reactive oxygen species; WT: wild-type; GC: gamma-glutamylcysteine.

\section{Competing interests}

The authors declare that they have no competing interests.

\section{Authors' contributions}

KMK and JRL drafted the manuscript. JRL and SL performed majority of the experimental work. CD contributed to the in vitro protein analysis. VKG contributed to the in vivo protein analysis. JRL, SL, ALL, GG, TM, ARW, JK, and KMK contributed to the conception, design, analysis, and interpretation of the data. All authors read and approved the final manuscript.

\section{Acknowledgements}

We gratefully acknowledge Prof. Masayuki Yamamoto (Tohoku University) for the provision of Nrf2-deficient mice and thank Ms. Laila Kaskela, Ms. Mirka Tikkanen, Ms. Sara Wojciechowski, Ms. Riitta Kauppinen, and Ms. Raisa Giniatullina for technical assistance. This study was supported by The Sigrid Juselius Foundation, The Academy of Finland, and The Finnish Cultural Foundation. JRL is supported by a National Health and Medical Research Council Peter Doherty Fellowship. The funding sources had no role in the study design, data collection and analysis, preparation of the manuscript, or decision to publish.

\section{Author details}

${ }^{1}$ Department of Pathology, The University of Melbourne, Parkville, Victoria, Australia. ${ }^{2}$ Mental Health Research Institute of Victoria, Parkville, Victoria, 
Australia. ${ }^{3}$ Department of Neurobiology, A.I. Virtanen Institute for Molecular Sciences, University of Eastern Finland, Kuopio, Finland. ${ }^{4}$ Department of Biotechnology and Molecular Medicine, A.I. Virtanen Institute for Molecular Sciences, University of Eastern Finland, Kuopio, Finland.

\section{Received: 18 January 2016 Accepted: 18 February 2016}

Published online: 26 February 2016

\section{References}

1. Barnham KJ, Masters CL, Bush Al. Neurodegenerative diseases and oxidative stress. Nat Rev Drug Discov. 2004;3:205-14.

2. Pratico D. Evidence of oxidative stress in Alzheimer's disease brain and antioxidant therapy: lights and shadows. Ann N Y Acad Sci. 2008;1147:70-8.

3. Valko M, Leibfritz D, Moncol J, Cronin MT, Mazur M, Telser J. Free radicals and antioxidants in normal physiological functions and human disease. Int J Biochem Cell Biol. 2007:39:44-84.

4. Kaspar JW, Niture SK, Jaiswal AK. Nrf2:INrf2 (Keap1) signaling in oxidative stress. Free Radic Biol Med. 2009;47:1304-9.

5. Inamdar NM, Ahn Yl, Alam J. The heme-responsive element of the mouse heme oxygenase-1 gene is an extended AP-1 binding site that resembles the recognition sequences for MAF and NF-E2 transcription factors. Biochem Biophys Res Commun. 1996;221:570-6.

6. Jaiswal AK. Nrf2 signaling in coordinated activation of antioxidant gene expression. Free Radic Biol Med. 2004;36:1199-207.

7. Mulcahy RT, Wartman MA, Bailey HH, Gipp JJ. Constitutive and betanaphthoflavone-induced expression of the human gamma-glutamylcysteine synthetase heavy subunit gene is regulated by a distal antioxidant response element/TRE sequence. J Biol Chem. 1997;272:7445-54.

8. Niture SK, Khatri R, Jaiswal AK. Regulation of Nrf2-an update. Free Radic Biol Med. 2014;66:36-44

9. Zhang M, An C, Gao Y, Leak RK, Chen J, Zhang F. Emerging roles of Nrf2 and phase II antioxidant enzymes in neuroprotection. Prog Neurobiol. 2013;100:30-47.

10. Kraft AD, Johnson DA, Johnson JA. Nuclear factor E2-related factor 2dependent antioxidant response element activation by tertbutylhydroquinone and sulforaphane occurring preferentially in astrocytes conditions neurons against oxidative insult. J Neurosci. 2004;24:1101-12.

11. Steele ML, Fuller S, Patel M, Kersaitis C, Ooi L, Munch G. Effect of Nrf2 activators on release of glutathione, cysteinylglycine and homocysteine by human U373 astroglial cells. Redox Biol. 2013;1:441-5.

12. Ramsey CP, Glass CA, Montgomery MB, Lindl KA, Ritson GP, Chia LA, et al. Expression of Nrf2 in neurodegenerative diseases. J Neuropathol Exp Neurol. 2007;66:75-85

13. Kanninen K, Malm TM, Jyrkkanen HK, Goldsteins G, Keksa-Goldsteine V, Tanila $\mathrm{H}$, et al. Nuclear factor erythroid 2-related factor 2 protects against beta amyloid. Mol Cell Neurosci. 2008;39:302-13.

14. Choudhry F, Howlett DR, Richardson JC, Francis PT, Williams RJ. Pro-oxidant diet enhances beta/gamma secretase-mediated APP processing in APP/PS1 transgenic mice. Neurobiol Aging. 2012;33:960-8.

15. Joshi G, Gan KA, Johnson DA, Johnson JA. Increased Alzheimer's disease-like pathology in the APP/ PS1DeltaE9 mouse model lacking Nrf2 through modulation of autophagy. Neurobiol Aging. 2015;36:664-79.

16. Kanninen $\mathrm{K}$, Heikkinen $\mathrm{R}, \mathrm{Malm} \mathrm{T}$, Rolova $\mathrm{T}$, Kuhmonen $\mathrm{S}$, Leinonen $\mathrm{H}$, et al. Intrahippocampal injection of a lentiviral vector expressing Nrf2 improves spatial learning in a mouse model of Alzheimer's disease. Proc Natl Acad Sci U S A. 2009;106:16505-10.

17. Prestera $T$, Holtzclaw WD, Zhang $Y$, Talalay P. Chemical and molecular regulation of enzymes that detoxify carcinogens. Proc Natl Acad Sci U S A. 1993:90:2965-9.

18. Erlank H, Elmann A, Kohen R, Kanner J. Polyphenols activate Nrf2 in astrocytes via $\mathrm{H} 2 \mathrm{O} 2$, semiquinones, and quinones. Free Radic Biol Med. 2011:51:2319-27.

19. Turpaev KT. Keap1-Nrf2 signaling pathway: mechanisms of regulation and role in protection of cells against toxicity caused by xenobiotics and electrophiles. Biochemistry (Mosc). 2013;78:111-26.

20. Jin W, Ni H, Hou X, Ming X, Wang J, Yuan B, et al. Tert-butylhydroquinone protects the spinal cord against inflammatory response produced by spinal cord injury. Ann Clin Lab Sci. 2014:44:151-7.

21. Kim HV, Kim HY, Ehrlich HY, Choi SY, Kim DJ, Kim Y. Amelioration of Alzheimer's disease by neuroprotective effect of sulforaphane in animal model. Amyloid. 2013;20:7-12.
22. Ashabi G, Alamdary SZ, Ramin M, Khodagholi F. Reduction of hippocampal apoptosis by intracerebroventricular administration of extracellular signalregulated protein kinase and/or p38 inhibitors in amyloid beta rat model of Alzheimer's disease: involvement of nuclear-related factor-2 and nuclear factor-kappaB. Basic Clin Pharmacol Toxicol. 2013;112:145-55.

23. Akhter H, Katre A, Li L, Liu X, Liu RM. Therapeutic potential and antiamyloidosis mechanisms of tert-butylhydroquinone for Alzheimer's disease. J Alzheimers Dis. 2011;26:767-78.

24. Deeks ED. Dimethyl fumarate: a review in relapsing-remitting MS. Drugs. 2016:76:243-54.

25. Wild AC, Moinova HR, Mulcahy RT. Regulation of gamma-glutamylcysteine synthetase subunit gene expression by the transcription factor Nrf2. J Biol Chem. 1999:274:33627-36.

26. Zipper LM, Mulcahy RT. Erk activation is required for Nrf2 nuclear localization during pyrrolidine dithiocarbamate induction of glutamate cysteine ligase modulatory gene expression in HepG2 cells. Toxicol Sci. 2003;73:124-34.

27. Borrello S, Demple B. NF kappa B-independent transcriptional induction of the human manganous superoxide dismutase gene. Arch Biochem Biophys. 1997;348:289-94.

28. Hartsfield CL, Alam J, Choi AM. Transcriptional regulation of the heme oxygenase 1 gene by pyrrolidine dithiocarbamate. Faseb j. 1998;12:1675-82.

29. Stuhlmeier KM. Activation and regulation of Hsp32 and Hsp70. Eur J Biochem. 2000;267:1161-7.

30. Hayakawa M, Miyashita H, Sakamoto I, Kitagawa M, Tanaka H, Yasuda H, et al. Evidence that reactive oxygen species do not mediate NF-kappaB activation. Embo j. 2003;22:3356-66.

31. Liu SF, Ye X, Malik AB. Inhibition of NF-kappaB activation by pyrrolidine dithiocarbamate prevents in vivo expression of proinflammatory genes. Circulation. 1999;100:1330-7.

32. Schreck R, Meier B, Mannel DN, Droge W, Baeuerle PA. Dithiocarbamates as potent inhibitors of nuclear factor kappa B activation in intact cells. J Exp Med. 1992:175:1181-94.

33. Verhaegen S, McGowan AJ, Brophy AR, Fernandes RS, Cotter TG. Inhibition of apoptosis by antioxidants in the human HL-60 leukemia cell line. Biochem Pharmacol. 1995;50:1021-9.

34. Nurmi A, Goldsteins G, Narvainen J, Pihlaja R, Ahtoniemi T, Grohn O, et al. Antioxidant pyrrolidine dithiocarbamate activates Akt-GSK signaling and is neuroprotective in neonatal hypoxia-ischemia. Free Radic Biol Med. 2006:40: 1776-84.

35. Nurmi A, Vartiainen N, Pihlaja R, Goldsteins G, Yrjanheikki J, Koistinaho J. Pyrrolidine dithiocarbamate inhibits translocation of nuclear factor kappa-B in neurons and protects against brain ischaemia with a wide therapeutic time window. J Neurochem. 2004;91:755-65.

36. Lv R, Xu X, Luo Z, Shen N, Wang F, Zhao Y. Pyrrolidine dithiocarbamate (PDTC) inhibits the overexpression of MCP-1 and attenuates microglial activation in the hippocampus of a pilocarpine-induced status epilepticus rat model. Exp Ther Med. 2014;7:39-45.

37. Wang Z, Zhao H, Peng S, Zuo Z. Intranasal pyrrolidine dithiocarbamate decreases brain inflammatory mediators and provides neuroprotection after brain hypoxia-ischemia in neonatal rats. Exp Neurol. 2013;249:74-82.

38. Kim BK, Shin EJ, Kim HC, Chung YH, Dang DK, Jung BD, et al. Plateletactivating factor receptor knockout mice are protected from MPTP-induced dopaminergic degeneration. Neurochem Int. 2013;63:121-32.

39. Soerensen J, Pekcec A, Fuest C, Nickel A, Potschka H. Pyrrolidine dithiocarbamate protects the piriform cortex in the pilocarpine status epilepticus model. Epilepsy Res. 2009;87:177-83.

40. Shin EJ, Jhoo JH, Kim WK, Jhoo WK, Lee C, Jung BD, et al. Protection against kainate neurotoxicity by pyrrolidine dithiocarbamate. Clin Exp Pharmacol Physiol. 2004;31:320-6.

41. Malm TM, livonen H, Goldsteins G, Keksa-Goldsteine V, Ahtoniemi T, Kanninen K, et al. Pyrrolidine dithiocarbamate activates Akt and improves spatial learning in APP/PS1 mice without affecting beta-amyloid burden. J Neurosci. 2007;27:3712-21.

42. Cheng G, Whitehead SN, Hachinski V, Cechetto DF. Effects of pyrrolidine dithiocarbamate on beta-amyloid (25-35)-induced inflammatory responses and memory deficits in the rat. Neurobiol Dis. 2006;23:140-51.

43. Karkkainen V, Pomeshchik Y, Savchenko E, Dhungana H, Kurronen A, Lehtonen S, et al. Nrf2 regulates neurogenesis and protects neural progenitor cells against Abeta toxicity. Stem Cells. 2014;32:1904-16.

44. Itoh K, Chiba T, Takahashi S, Ishii T, Igarashi K, Katoh Y, et al. An Nrf2/small Maf heterodimer mediates the induction of phase II detoxifying enzyme 
genes through antioxidant response elements. Biochem Biophys Res Commun. 1997;236:313-22.

45. Pihlaja R, Koistinaho J, Malm T, Sikkila H, Vainio S, Koistinaho M. Transplanted astrocytes internalize deposited beta-amyloid peptides in a transgenic mouse model of Alzheimer's disease. Glia. 2008;56:154-63.

46. Hamprecht B, Loffler F. Primary glial cultures as a model for studying hormone action. Methods Enzymol. 1985;109:341-5.

47. Liddell JR, Obando D, Liu J, Ganio G, Volitakis I, Mok SS, et al. Lipophilic adamantyl- or deferasirox-based conjugates of desferrioxamine B have enhanced neuroprotective capacity: implications for Parkinson disease. Free Radic Biol Med. 2013;60:147-56.

48. White CC, Viernes H, Krejsa CM, Botta D, Kavanagh TJ. Fluorescence-based microtiter plate assay for glutamate-cysteine ligase activity. Anal Biochem. 2003;318:175-80.

49. Tietze F. Enzymic method for quantitative determination of nanogram amounts of total and oxidized glutathione: applications to mammalian blood and other tissues. Anal Biochem. 1969;27:502-22.

50. Liddell JR, Robinson SR, Dringen R, Bishop GM. Astrocytes retain their antioxidant capacity into advanced old age. Glia. 2010;58:1500-9.

51. Naumenko N, Pollari E, Kurronen A, Giniatullina R, Shakirzyanova A, Magga J, et al. Gender-specific mechanism of synaptic impairment and its prevention by GCSF in a mouse model of ALS. Front Cell Neurosci. 2011:5:26.

52. Ding K, Wang H, Xu J, Li T, Zhang L, Ding Y, et al. Melatonin stimulates antioxidant enzymes and reduces oxidative stress in experimental traumatic brain injury: the Nrf2-ARE signaling pathway as a potential mechanism. Free Radic Biol Med. 2014;73:1-11.

53. Li T, Wang $H$, Ding $Y$, Zhou $M$, Zhou $X$, Zhang $X$, et al. Genetic elimination of Nrf2 aggravates secondary complications except for vasospasm after experimental subarachnoid hemorrhage in mice. Brain Res. 2014;1558:90-9.

54. Wang W, Wu Y, Zhang G, Fang $H$, Wang $H$, Zang $H$, et al. Activation of Nrf2ARE signal pathway protects the brain from damage induced by epileptic seizure. Brain Res. 2014;1544:54-61.

55. Leonardo CC, Agrawal M, Singh N, Moore JR, Biswal S, Dore S. Oral administration of the flavanol (-)-epicatechin bolsters endogenous protection against focal ischemia through the Nrf2 cytoprotective pathway. Eur J Neurosci. 2013;38:3659-68.

56. Gan L, Vargas MR, Johnson DA, Johnson JA. Astrocyte-specific overexpression of $\mathrm{Nrf2}$ delays motor pathology and synuclein aggregation throughout the CNS in the alpha-synuclein mutant (A53T) mouse model. J Neurosci. 2012;32:17775-87.

57. Chen PC, Vargas MR, Pani AK, Smeyne RJ, Johnson DA, Kan YW, et al. Nrf2mediated neuroprotection in the MPTP mouse model of Parkinson's disease: critical role for the astrocyte. Proc Natl Acad Sci U S A. 2009;106:2933-8.

58. Vargas MR, Johnson DA, Sirkis DW, Messing A, Johnson JA. Nrf2 activation in astrocytes protects against neurodegeneration in mouse models of familial amyotrophic lateral sclerosis. J Neurosci. 2008;28:13574-81.

59. Shih $A Y$, Johnson DA, Wong G, Kraft AD, Jiang $L$, Erb $H$, et al. Coordinate regulation of glutathione biosynthesis and release by Nrf2-expressing glia potently protects neurons from oxidative stress. J Neurosci. 2003;23:3394-406.

60. Bell KF, Al-Mubarak BB, Martel MA, McKay S, Wheelan N, Hasel P, et al. Neuronal development is promoted by weakened intrinsic antioxidan defences due to epigenetic repression of Nrf2. Nat Commun. 2015;6:7066.

61. Habas A, Hahn J, Wang X, Margeta M. Neuronal activity regulates astrocytic Nrf2 signaling. Proc Natl Acad Sci U S A. 2013;110:18291-6.

62. Kurronen A, Pihlaja R, Pollari E, Kanninen K, Storvik M, Wong G, et al. Adult and neonatal astrocytes exhibit diverse gene expression profiles in response to beta amyloid ex vivo. World J Neurosci. 2012;2:57-67.

63. Cuadrado A, Martin-Moldes Z, Ye J, Lastres-Becker I. Transcription factors NRF2 and NF-kappaB are coordinated effectors of the Rho family, GTPbinding protein RAC1 during inflammation. J Biol Chem. 2014;289:15244-58.

64. Wakabayashi N, Slocum SL, Skoko JJ, Shin S, Kensler TW. When NRF2 talks, who's listening? Antioxid Redox Signal. 2010;13:1649-63.

65. Liu GH, Qu J, Shen X. NF-kappaB/p65 antagonizes Nrf2-ARE pathway by depriving CBP from Nrf2 and facilitating recruitment of HDAC3 to MafK. Biochim Biophys Acta. 2008;1783:713-27.

66. Salazar M, Rojo Al, Velasco D, de Sagarra RM, Cuadrado A. Glycogen synthase kinase-3beta inhibits the xenobiotic and antioxidant cell response by direct phosphorylation and nuclear exclusion of the transcription factor Nrf2. J Biol Chem. 2006;281:14841-51.
67. Rojo Al, Sagarra MR, Cuadrado A. GSK-3beta down-regulates the transcription factor Nrf2 after oxidant damage: relevance to exposure of neuronal cells to oxidative stress. J Neurochem. 2008;105:192-202.

68. Jain AK, Jaiswal AK. Phosphorylation of tyrosine 568 controls nuclear export of Nrf2. J Biol Chem. 2006;281:12132-42.

69. Jain AK, Jaiswal AK. GSK-3beta acts upstream of Fyn kinase in regulation of nuclear export and degradation of NF-E2 related factor 2. J Biol Chem. 2007; 282:16502-10.

70. Bica L, Crouch PJ, Cappai R, White AR. Metallo-complex activation of neuroprotective signalling pathways as a therapeutic treatment for Alzheimer's disease. Mol Biosyst. 2009:5:134-42.

71. Gomez-Ramos A, Dominguez J, Zafra D, Corominola H, Gomis R, Guinovart $J$ J, et al. Inhibition of GSK3 dependent tau phosphorylation by metals. Curr Alzheimer Res. 2006;3:123-7.

72. Nobel Cl, Kimland M, Lind B, Orrenius S, Slater AF. Dithiocarbamates induce apoptosis in thymocytes by raising the intracellular level of redox-active copper. J Biol Chem. 1995;270:26202-8.

73. Verhaegh GW, Richard MJ, Hainaut P. Regulation of p53 by metal ions and by antioxidants: dithiocarbamate down-regulates p53 DNA-binding activity by increasing the intracellular level of copper. Mol Cell Biol. 1997;17:5699-706.

74. Opazo CM, Greenough MA, Bush Al. Copper: from neurotransmission to neuroproteostasis. Front Aging Neurosci. 2014:6:143.

75. Grubman A, White AR. Copper as a key regulator of cell signalling pathways. Expert Rev Mol Med. 2014;16, e11.

76. Turski ML, Brady DC, Kim HJ, Kim BE, Nose Y, Counter CM, et al. A novel role for copper in Ras/mitogen-activated protein kinase signaling. Mol Cell Biol. 2012;32:1284-95.

77. Ostrakhovitch EA, Lordnejad MR, Schliess F, Sies H, Klotz LO. Copper ions strongly activate the phosphoinositide-3-kinase/Akt pathway independent of the generation of reactive oxygen species. Arch Biochem Biophys. 2002; 397:232-9.

78. Kanninen K, White AR, Koistinaho J, Malm T. Targeting glycogen synthase kinase-3beta for therapeutic benefit against oxidative stress in Alzheimer's disease: involvement of the Nrf2-ARE pathway. Int J Alzheimers Dis. 2011; 2011:985085.

79. Jiang WD, Liu Y, Hu K, Jiang J, Li SH, Feng L, et al. Copper exposure induces oxidative injury, disturbs the antioxidant system and changes the Nrf2/ARE (CuZnSOD) signaling in the fish brain: protective effects of myo-inositol. Aquat Toxicol. 2014;155:301-13.

80. Song MO, Mattie MD, Lee $\mathrm{CH}$, Freedman JH. The role of Nrf1 and Nrf2 in the regulation of copper-responsive transcription. Exp Cell Res. 2014;322:39-50.

81. McMahon M, Lamont DJ, Beattie KA, Hayes JD. Keap1 perceives stress via three sensors for the endogenous signaling molecules nitric oxide, zinc, and alkenals. Proc Natl Acad Sci U S A. 2010;107:18838-43.

82. Hanger DP, Hughes K, Woodgett JR, Brion JP, Anderton BH. Glycogen synthase kinase-3 induces Alzheimer's disease-like phosphorylation of tau: generation of paired helical filament epitopes and neuronal localisation of the kinase. Neurosci Lett. 1992;147:58-62.

83. White AR, Du T, Laughton KM, Volitakis I, Sharples RA, Xilinas ME, et al. Degradation of the Alzheimer disease amyloid beta-peptide by metaldependent up-regulation of metalloprotease activity. J Biol Chem. 2006;281: 17670-80.

84. Ham D, Schipper HM. Heme oxygenase-1 induction and mitochondrial iron sequestration in astroglia exposed to amyloid peptides. Cell Mol Biol (Noisy-le-grand). 2000;46:587-96.

85. Schipper HM, Song W, Zukor H, Hascalovici JR, Zeligman D. Heme oxygenase-1 and neurodegeneration: expanding frontiers of engagement. J Neurochem. 2009;110:469-85

86. Lavrovsky Y, Schwartzman ML, Levere RD, Kappas A, Abraham NG. Identification of binding sites for transcription factors NF-kappa B and AP-2 in the promoter region of the human heme oxygenase 1 gene. Proc Natl Acad Sci U S A. 1994:91:5987-91.

87. Brouard S, Berberat PO, Tobiasch E, Seldon MP, Bach FH, Soares MP. Heme oxygenase-1-derived carbon monoxide requires the activation of transcription factor NF-kappa B to protect endothelial cells from tumor necrosis factor-alpha-mediated apoptosis. J Biol Chem. 2002;277:17950-61.

88. Herculano-Houzel S, Mota B, Lent R. Cellular scaling rules for rodent brains. Proc Natl Acad Sci U S A. 2006:103:12138-43.

89. Herculano-Houzel S. The glia/neuron ratio: how it varies uniformly across brain structures and species and what that means for brain physiology and evolution. Glia. 2014;62:1377-91. 